\title{
TOURAINE E BOURDIEU NAS CIÊNCIAS SOCIAIS BRASILEIRAS: DUAS RECEPÇÕES DIFERENCIADAS
}

Ao ter a ocasião de retomar o tema da recepção da obra de Pierre Bourdieu no Brasil, faço-o a partir da comparação com a recepção de outro sociólogo francês, Alain Touraine, anteriormente implantado na circulação de ideias e redes de pesquisadores entre os dois países. De fato, a recepção da obra ${ }^{1}$ de Bourdieu no Brasil poderia ser, à primeira vista, surpreendente, dada a presença direta de Alain Touraine no país, bem como na América Latina, haja vista a posição concorrencial dos dois autores no campo da Sociologia francesa desde meados dos anos 1960. Esta aproximação justifica-se, além disso, pelo fato de minha análise anterior da recepção de Bourdieu ter sido feita a partir de seus efeitos sobre a "renovação das análises das classes populares brasileiras" (ver Leite Lopes, 2003a, 2003b, 2005). ${ }^{2}$ Ora, a presença de Touraine no Brasil tem por origem sua importância na fundação de um Centro de Sociologia Industrial e do Trabalho pertencente à Cadeira de Sociologia I da Universidade de São Paulo (USP), a partir de seu investimento anterior nesta especialidade sociológica na França e no Chile. Ele vem assim, durante a missão na USP em 1960, que lhe é atribuída por seu ex-mentor no Centre d'Études Sociologiques, Georges Friedmann, legitimar estudos que incluíam os trabalhadores industriais como objeto de destaque ao lado dos estudos sobre empresários que também vinham sendo desenhados no Brasil.

A trajetória dos dois autores no que diz respeito à sua relação com o campo das ciências sociais brasileiras pode ser uma pista interessante para 
o conhecimento de aspectos deste mesmo campo no que se refere à sua inserção na circulação internacional de ideias e de pesquisadores. Por outro lado, este exame comparativo, ao ser feito quando a suposta concorrência entre os dois autores está de certo modo ultrapassada desde o próprio amadurecimento da carreira divergente de ambos, pode ser mais frutífero do que em períodos anteriores de maior rivalidade das respectivas "escolas de pensamento". De fato, com a morte de Bourdieu após uma intensa penetração internacional de sua obra, em particular no polo dominante dos países anglo-saxônicos nos anos 1990, destacaram-se, dentre as declarações à imprensa que se seguiram ao falecimento do sociólogo controvertido na mídia e no campo intelectual, as de Touraine, ao fazer o reconhecimento da singularidade e da fecundidade da obra deste directeur d'études concorrente. ${ }^{3}$ Além disso, a diversificação dos próprios pesquisadores no interior dos centros de pesquisa relacionados a um e outro diretor de estudos no interior da École des Hautes Études en Sciences Sociales e em outras instituições de ciências sociais, fazendo, de certa forma, cruzar pertencimentos anteriormente opostos, vem contribuir para atenuar uma dentre as famosas rivalidades no campo francês assinaladas por Eric Hobsbawm em suas memórias.

Acima está dito uma "suposta" rivalidade, na medida em que se torna difícil ilustrá-la com textos escritos. Na recente biografia de Bourdieu com farta consulta à documentação disponível feita por Lescourret (2008), por exemplo, Touraine não aparece no índice de nomes citados e, portanto, parece inexistente no livro (na verdade seu nome aparece mencionado numa passagem do livro, mas não é transposto para o índice). No estado atual da literatura sobre a história social e intelectual do campo sociológico francês as referências a esta concorrência entre diretores de estudos não aparece de forma explícita. ${ }^{4} \mathrm{O}$ próprio Touraine, em capítulo para o livro L'état des sciences sociales en France (Guillaume, 1986: 139), classifica Bourdieu ao seu lado no que ele denomina de Sociologia do Conflito, por oposição a sociólogos preocupados com uma Sociologia da Integração (Crozier e Boudon); mas ao mesmo tempo ambos se distanciariam, pois enquanto Bourdieu é classificado como estruturalista crítico, ele mesmo, Touraine, se vê como um sociólogo da ação. No mesmo artigo Touraine reconhece a vitalidade da revista criada e dirigida por Bourdieu, Actes de la Recherche en Sciences Sociales. A rivalidade operaria muito mais na área de informalidade institucional não escrita e nas suas consequências. 


\section{TOURAINE E A CONSOLIDAÇÃO DA SOCIOLOGIA DA USP NOS ANOS 1960 E 1970}

Cinco anos separam Touraine - nascido em 1925 e formado pela École Normale Supérieure como agrégé de História em 1950 -, de Bourdieu, nascido em 1930 e formado em 1955, agrégé de Filosofia. O primeiro entrou como diretor de estudos na École de Hautes Études en Sciences Sociales (EHESS) em 1960, o segundo em 1964.

A primeira vinda ao Brasil de Alain Touraine se deu em 1960, em uma missão na USP. Segundo seu relato, uma demanda teria sido feita a Georges Friedmann, presidente da Associação Internacional de Sociologia (ISA) entre 1956 e 1959, por parte de Fernando de Azevedo e a Cadeira de Sociologia II da USP, para que uma cooperação se estabelecesse em torno da Sociologia do Trabalho, área a ser reforçada na USP; a demanda teria sido canalizada para ele.

Foi talvez por intermédio da Associação Internacional de Sociologia [ISA] da qual Friedmann era o presidente [que chegou pedido da USP para o envio de especialista em Sociologia Industrial], mas a mesma demanda finalmente me foi feita pela USP e, portanto, eu fui; aliás, foi divertido porque eu fui ensinar no quadro das atividades da Cadeira 2, isto é Fernando de Azevedo... E depois de dois meses mais ou menos, me pediram para eu especificar meus projetos, de fazer propostas, e eu disse: "Bem, eu acho que se deve criar um Centro de Sociologia do Trabalho e proponho que o seu diretor seja Fernando Henrique Cardoso". Foi um escândalo! Porque era a outra cadeira, a Cadeira 1. Então eu fui considerado um traidor. E como todos os traidores, eu mudei de lado e fiquei muito amigo de Fernando Henrique, de Octávio Ianni, desse pessoal... ${ }^{5}$

Touraine se atribui a ideia de constituir o Centro de Sociologia Industrial e do Trabalho (CESIT) e de sugerir a designação de Fernando Henrique Cardoso, então assistente do chefe da Cadeira de Sociologia I, Florestan Fernandes, para dirigir o Centro. Ele estaria se associando, assim, ao mito de origem deste centro e à sociologia do trabalho brasileira nascente. ${ }^{6}$ Ele continuaria, ao longo da vida, a manter relações com os então pesquisadores do CESIT e da Cadeira de Sociologia I da USP, em particular com Fernando Henrique, a quem convidou para ser professor na Universidade de Nanterre entre 1967 e 1968. E dirigiria a tese de muitos doutorandos brasileiros (e latino-americanos) ao longo das décadas seguintes. ${ }^{7}$

De acordo com seu investimento na Sociologia Industrial, Touraine centrou todas as suas atenções no que diz respeito ao Brasil em São Paulo, diferenciando-se de Roger Bastide, antigo ocupante da Cadeira de Sociologia I, que já havia retornado à França em meados dos anos $1950 .^{8}$

Durante sua primeira estadia em São Paulo, Touraine pôde se encontrar com o conjunto dos pesquisadores de Sociologia (de ambas as Cadeiras) e em especial com aqueles que já vinham desenvolvendo pesquisas sobre trabalho e trabalhadores, como era o caso de Juarez Brandão Lopes e de Azis Simão, 
dos quais ele publicaria artigos em 1961, em número especial da revista Sociologie du Travail, em seu terceiro ano de edição (além de um artigo de Fernando Henrique Cardoso e um dele próprio Touraine, sobre "a consciência operária em São Paulo"). Juarez Brandão Lopes, como Touraine, nascido em 1925, havia feito sua graduação na Escola de Sociologia e Política e, com uma recomendação de Donald Pierson, professor da Escola originário da Universidade de Chicago onde fora orientado por Robert Park, para Chicago se dirigiu com a finalidade de fazer sua pós-graduação (que acabou sendo seu mestrado), seguindo os passos de Mario Wagner Vieira da Cunha e de Oracy Nogueira. Touraine também passara um ano nos EUA com bolsa Fullbright no início dos anos 1950, mas o fizera em Harvard, com visitas a Columbia e a Chicago. Na visita a Chicago fez um levantamento sobre o sindicalismo estadunidense. Embora com desconfianças políticas quanto ao establishment universitário americano, Touraine fora enviado (pelo Centre d'Études Sociologiques) aos EUA com uma bolsa da Fundação Rockefeller para inteirar-se dos procedimentos de pesquisa sociológicos considerados avançados naquele momento, em particular aqueles formulados por Parsons, Merton e Lazarsfeld. Este era o paradigma sociológico de dirigentes do CES, como Georges Gurvitch, Jean Stotzel, ou mesmo de Georges Friedmann.

Além de Juarez Brandão Lopes, que possuía este capital escolar internacional de ter passado pela Universidade de Chicago, outros sociólogos lidavam com o tema do trabalho nos anos 1950 no Brasil. Azis Simão, que havia vivenciado o sindicalismo do início dos anos 1930 e se tornara estudioso das transformações por que passavam os sindicatos em sua relação com o Estado, o que fazia no interior da Cadeira II da USP; Evaristo de Moraes Filho, autor do livro O problema do sindicato único no Brasil (1951), mas situado entre o Direito e a Sociologia, entre o Ministério do Trabalho e a Faculdade Nacional de Filosofia do Rio de Janeiro, não se tornara visível para o empreendimento sociológico mais estrito da USP; José Albertino Rodrigues, formado pela Escola de Sociologia e Política como Juarez, assistente da Cadeira de História Econômica da USP (da mesma forma que Fernando Henrique) até 1955, estava, desde a segunda metade dos anos 1950, trabalhando na criação da assessoria técnica aos sindicatos de trabalhadores (no Departamento Intersindical de Estudos Estatísticos e Sócio-Econômicos, o DIEESE) e, portanto, era menos visível para Touraine durante a sua passagem por dois meses na USP em 1960. Leôncio Martins Rodrigues ainda era estudante de Florestan Fernandes e de Fernando Henrique e seria, logo a seguir, um participante do CESIT e um dos sociólogos mais próximos às temática de Touraine dos anos 1960 e 1970 (ver Leite Lopes, Pessanha \& Ramalho, 2012).

Antes de sua vinda ao Brasil, Touraine já tinha uma experiência mais duradoura com o reforço internacional à implantação da Sociologia do Trabalho na Universidade do Chile. Também ali a demanda chilena, através do 
diretor do Instituto de Sociologia da Universidade do Chile, Eduardo Hamuy, que havia feito sua formação na Universidade de Columbia (ver Blanco, 2007), se dirigiu a Georges Friedmann, com sua posição de evidência internacional na Associação Internacional de Sociologia (ISA), e este incumbiu seus pesquisadores no Centre d'Études Sociologiques do Centre National de la Recherche Scientifique (CNRS), Alain Touraine, Jean Daniel Reynaud e Lucien Brams a partilharem missões sucessivas de seis meses na implantação do ensino e da pesquisa sobre a sociologia do trabalho na Universidade do Chile. ${ }^{9}$

A estadia de Touraine no Chile entre julho de 1956 e janeiro de 1957 lhe proporcionou o início de uma ligação mais profunda com este país e a América Latina. Ele se casou com uma chilena, Adriana Arenas Pizzarro, e passou a fazer parte das redes de sociólogos latino-americanos daí por diante. Com a sua experiência de pesquisa anterior na França, a saber, seu trabalho sobre os operários e a evolução técnica nas Fábricas Renault, ${ }^{10}$ além de sua participação nas pesquisas coletivas do CES na siderurgia em Mont Saint-Martin, Longwy, no Leste da França, bem como ainda na amostragem nacional sobre os operários industriais na França, Touraine se habilitava para conceber uma pesquisa sobre a mineração e a siderurgia no Chile. ${ }^{11}$ Assim como o diretor do Instituto de Sociologia da Universidade do Chile, Eduardo Hamuy, também ele havia estudado nas universidades da Costa Leste estadunidense e se familiarizado com as metodologias quantitativas da sociologia dominante de então naquelas universidades, e as havia praticado no trabalho coletivo de seu centro de pesquisa na França. ${ }^{12}$ Tal trabalho coletivo também expressava algo como uma hierarquia de tarefas, de forma que a concepção da pesquisa, a execução do questionário em campo, o tratamento dos dados quantitativos e a redação final pudessem ser dissociados e realizados ou dirigidos por pesquisadores diferentes (Di Tella et al., 1966).

Alguns pontos comuns com a pesquisa de Juarez Brandão Lopes, que serviu de base aos seus livros Crise do Brasil arcaico (1967) e Sociedade industrial no Brasil (1964) aparecem. Pode-se notar que, paralelamente, sem se comunicarem, Brandão Lopes e Touraine escolhem, ambos, comunidades de operários industriais para estudar de forma comparativa: uma, mais "tradicional", submetida a formas de dominação autoritárias; outra, mais recente, sob formas de dominação mais modernas, mais profissionais. Este é o caso do par "Sobrado e Mundo Novo", no caso de Juarez; e de "Lota e Huachipato", no caso de Touraine. ${ }^{13}$ Em Crise do Brasil arcaico as duas cidades abrigam indústrias têxteis; no caso da pesquisa chilena a comparação é feita entre uma empresa de mineração e uma empresa siderúrgica (como no estudo mencionado de Barrington Moore Jr.). Além desta coincidência de estratégia comparativa, há uma outra, de ordem temática: o estudo dos operários de origem rural. Em Sociedade industrial no Brasil, Brandão Lopes ([1964] 1971) analisa, ao lado dos operários qualificados da indústria de São Paulo, a existência de um grande con- 
tingente de trabalhadores industriais recentes de origem rural. ${ }^{14}$ No artigo que Touraine dedica à "consciência operária em São Paulo", no número de Sociologie du Travail de 1961 onde ele organiza um dossiê de artigos de sociólogos da USP estudiosos do trabalho, é dada importância a esta característica da força de trabalho industrial nas fábricas de São Paulo, que de resto passa a ter lugar central nas análises sociológicas de então sobre o assunto. Em 1961 Touraine assina, com Orietta Ragazzi, a publicação de um relatório de pesquisa sobre os operários de origem agrícola na França (Touraine \& Ragazzi, 1961). ${ }^{15}$

No entanto à diferença do tratamento qualitativo das entrevistas e observações feitas por Brandão Lopes na fábrica de autopeças Metal Leve, de São Paulo, bem como nas cidades de Leopoldina e Cataguases, em Minas Gerais, ambas as pesquisas inseridas nos estudos de comunidade das cidades-laboratório do Centro Brasileiro de Pesquisas Educacionais (CBPE); os estudos acima mencionados em que Touraine participou no Chile ou na França foram realizados sob a mecânica de equipes tendo por instrumento de registro o questionário, seguido de relatórios comentando os dados numéricos dispostos em tabelas.

Se no livro L'évolution du travail ouvrier aux usines Renault, publicado em 1955, mas baseado em pesquisa do final dos anos 1940 (em torno de 1948), há o uso de observação direta nos postos de trabalho, bem como de uma análise, baseada na documentação histórica, voltada para a relação dos operários com as máquinas e processos de fabricação, nos estudos posteriores realizados em meados dos anos 1950, quando vários membros do Centre d'Études Sociologiques haviam feito estágios nos Estados Unidos, sobretudo nas universidades da Costa Leste (como Touraine, bolsista Rockefeller nas universidades de Harvard, Columbia e Chicago entre setembro de 1952 e setembro de 1953), o procedimento adotado é o da equipe trabalhando sob um regime de divisão do trabalho em torno do instrumento do questionário e das tabelas quantitativas produzidas.

É interessante que as contribuições da Universidade de Chicago que então, nos anos 1940 e 1950, se desenvolviam em torno de sucessores de Robert Park, como Robert Redfield, Everett Hugues e Herbert Blumer - que mantinham (os dois últimos) uma agenda de pesquisa sociológica que se aproximava da agenda antropológica e etnográfica - não estão no horizonte de apropriações dos sociólogos bolsistas franceses enviados às universidades estadunidenses. (Tais autores de Chicago não passam despercebidos dos bolsistas brasileiros, alunos de Donald Pierson, procedentes da Escola de Sociologia e Política, como Mario Wagner Vieira da Cunha, Oracy Nogueira e Juarez Brandão Lopes, este último, aluno de Blumer e Louis Wirth no início dos anos 1950.) Apesar de uma apreciação crítica da sociologia norte-americana vista em bloco, ${ }^{16}$ os sociólogos franceses, vindos de uma formação literária e se 
considerando autodidatas ao enfrentarem suas primeiras pesquisas empíricas, se fascinam com os procedimentos estatísticos da survey research, com suas construções de amostragem, de definição de variáveis, de verificação de hipóteses, de testes estatísticos, do aprendizado de noções como a de "atitude"; procedimentos estes que passam a ser considerados como as técnicas legítimas de uma sociologia científica. Assim, o Laboratoire de Sociologie Industrielle, fundado por Touraine na EHESS em 1959, procura juntar as preocupações teóricas com as do domínio do rigor técnico, na apresentação que dele é feita no número 2 do primeiro ano da Reuue Française de Sociologie (1960: 218): insiste-se, ali, sobre o objetivo de "associar [no laboratório] pesquisadores desejosos de desenvolver um conjunto coerente de proposições teóricas e de elevar o nível técnico e metodológico de suas investigações" (apud Chapoulie, 1991: 356, nota 51). Para isto, o contato e o intercâmbio com o novo padrão de sociologia quantitativa das universidades da Costa Leste estadunidense foi importante, como indica o trecho de depoimento de Touraine: "Sendo eu totalmente autodidata, perdi muito tempo até chegar à minha estadia nos Estados Unidos como bolsista Rockefeller durante o ano [universitário] 1952-53" (apud Chapoulie, 1991: 353, nota 49).

Assim, o treinamento nas técnicas estatísticas que vinham promovendo uma parte da sociologia estadunidense à pretensão de sociologia científica aparece como uma aposta da geração de sociólogos franceses com autoridade nas instituições de pesquisa do pós-guerra na formação da geração seguinte. Isto aparece nos relatórios do Comitê Nacional do CNRS de acompanhamento dos pesquisadores a que teve acesso Lucie Tanguy. No relatório de Friedmann sobre as atividades de Touraine nos anos 1953-1954, aparece o efeito de disciplinamento desejado sobre este pesquisador, que havia entrado em 1950 no CNRS, aos 25 anos, recém-saído da École Normale Supérieure (ENS), onde havia feito uma dissertação de diploma de estudos superiores [mémoire de diplôme d'études supérieures] sobre "L'évolution du travail ouvrier aux usines Renault", orientado pelo historiador Ernest Labrousse. ${ }^{17}$ A apreciação de Gurvitch, que se soma à de Friedmann no mesmo dossiê, diz ainda: “[...] Nós ficamos satisfeitos de constatar que M. Touraine tinha adquirido uma boa iniciação de estatístico ${ }^{18}$ [...]. É um sujeito difícil de guiar e enquadrar mas desde que prossiga com sua maturação e se discipline, nós persistimos em pensar que seu futuro científico é muito promissor".

Após participar nas diversas pesquisas coletivas do CES e ter adquirido a formação desejada por seus supervisores, Touraine deixa aquele centro do CNRS, do qual era pesquisador, ao ser nomeado, em 1958, para professor na École Pratique des Hautes Études (depois EHESS), onde, apoiado por Fernand Braudel, organiza o Laboratoire de Sociologie Industrielle e passa a directeur d'études em 1960. Para isto, sem dúvida, sua atuação nas pesquisas sobre a indústria automobilística, a siderurgia e a mineração na França e no 
Chile (quanto a estes dois últimos setores), além das credenciais adquiridas nas parcerias internacionais quanto à difusão da sociologia do trabalho francesa no Chile e na Argentina, ${ }^{19}$ faziam valer seu estabelecimento como directeur d'études da EHESS. Como assinala Lucie Tanguy, “[...] o acesso ao estatuto de autor maior, num dado momento, depende da legitimidade adquirida perante seus pares (pelo seu uso da norma científica), mas também de sua capacidade de fornecer uma análise da sociedade como totalidade estruturada. A notoriedade de Touraine se estabelece a respeito do primado concedido aos conflitos e aos movimentos sociais [...] [notoriedade comparada às de Crozier e Reynaud quanto aos primados dados ao estudo das organizações e ao das negociações para a resolução de conflitos, respectivamente]" (Tanguy, 2011: 129). Esta busca por notoriedade leva a riscos quanto às grandes interpretações que são lançadas pelos autores. ${ }^{20}$

Já diretor do Laboratoire de Sociologie Industrielle desde 1958, Touraine funda, em seguida, em 1970, o Centre d'Études des Mouvements Sociaux e, em 1981, o Centre d'Analyse d'Intervention Sociologique, todos na École des Hautes Études en Sciences Sociales de Paris. Durante todo este período manteve contato com sociólogos brasileiros, bem como com latino-americanos.

\section{BOURDIEU E O AUMENTO DA AMPLITUDE DA RECEPÇÃO: DA ANTROPOLOGIA DO CAMPESINATO E DOS TRABALHADORES A UMA SOCIOLOGIA HISTÓRICA DAS ELITES INTELECTUAIS}

Diferentemente de Touraine, Bourdieu nunca esteve no Brasil ou na América Latina. A difusão inicial de suas obras se deveu à sua repercussão junto a alunos brasileiros, bolsistas em Paris, que se tornaram professores em instituições de ensino e pesquisa brasileiras. Quando Moacir Palmeira foi seu aluno, entre 1967 e 1969, na EHESS, Bourdieu já tinha tomado contato com o Brasil pelo menos através da resenha que fizera do livro de Bastide, Religiões africanas no Brasil, em 1961, no primeiro número da revista L'Homme, como assinalou Fernando Pinheiro Filho (2009). Os cursos que Palmeira fez com Bourdieu foram importantes para a feitura da sua tese de doutorado, Latifundium et capitalisme, lecture critique d'un débat (1971). No curso que por sua vez Palmeira deu no segundo semestre de 1970 no Programa de Pós-Graduação em Antropologia Social do Museu Nacional-UFRJ (PPGAS-MN-UFRJ), em que reconstruía o processo de feitura da tese refazendo com os alunos a análise crítica da literatura sobre a questão agrária brasileira com um instrumental de sociologia dos intelectuais e de suas obras, os primeiros artigos de Bourdieu sobre o assunto foram lidos e colocados num lugar acessível da caixa de ferramentas antropológica que os estudantes deste programa iam então incorporando. ${ }^{21}$ Nos cursos dados por Palmeira, logo seguido por outros colegas, 
sobre Sociedades Camponesas, os artigos: "Société traditionnelle: atitude à l'égard du temps et conduite économique", "Célibat et condition paysanne", bem como capítulos de Travail et travailleurs en Algérie e Le déracinement tornaram-se textos usuais. Esta conjugação de textos sobre sociologia da produção intelectual, bem como sobre etnologia cabila e do campesinato francês caracteriza a incorporação precoce e transversal da obra de Bourdieu no Brasil, diferentemente da que ocorre em outros campos de ciências sociais em outros países, em particular nos campos dominantes anglo-saxônicos. Na grande maioria destes outros campos nacionais a apreensão da obra de Bourdieu é mais tardia e se dá por campos e subdisciplinas especializadas e tornadas estanques, os sociólogos culturais e da educação ignorando a produção da etnologia do campesinato apropriada pelos antropólogos e vice-versa (ver indicações neste sentido em Calhoun, 2005: 241; Leite Lopes, 2005; Bourdieu, 2005: 325)..$^{22}$

Assim, além da tese de Palmeira, as obras de Bourdieu aparecem com destaque nas dissertações e teses, depois publicadas, de vários colegas que passaram pelo Museu Nacional. ${ }^{23}$ Também o decano do Museu Nacional nesta geração, o professor Luiz de Castro Faria, após uma produção antropológica clássica situada na etnologia e na arqueologia, se apropria da produção de Bourdieu e de Foucault em suas pesquisas sobre o pensamento social brasileiro. Pode-se observar que o texto do projeto "Emprego e mudança social no Nordeste", realizado no PPGAS-MN entre 1975 e 1977 e coordenado por Palmeira, envolvendo cerca de vinte pesquisadores, tem pontos de inspiração na discussão entre sociologia e estatística e na importância da reflexão sobre a produção de conhecimento em situações autoritárias de dominação social que permeiam Travail et travailleurs en Algérie e outras obras da fase argelina de Bourdieu. ${ }^{24}$ Este projeto representou uma expansão dos resultados alcançados no projeto coletivo sobre a Zona da Mata canavieira de Pernambuco para outras áreas rurais do Nordeste, para situações urbanas e industriais e para áreas do Norte do país, produzindo resultados nos seus relatórios e nas dissertações e teses futuras dos pesquisadores que dele participaram. Em artigo anterior sobre a recepção de Bourdieu no Brasil pude me estender sobre a formação deste grupo de pesquisa em torno de Palmeira, primeiramente através dos processos de transformação social na área da zona canavieira de Pernambuco que ele e Lygia Sigaud haviam iniciado em 1969 com um período de trabalho de campo, e que se seguiu com uma equipe maior no início de 1972. De lá pra cá outros relatos sobre tais projetos de pesquisa coletivos foram publicados e mais estão por vir. ${ }^{25}$

A apropriação da obra de Pierre Bourdieu por parte dos antropólogos que passaram pelo Museu Nacional tornou-se de certa forma um habitus científico, uma incorporação de instrumentos de trabalho. Embora alguns dentre eles tenham participado da tradução e publicação de algumas poucas obras 
de Bourdieu, como do artigo "Campo intelectual e projeto criador" e do livro Questões de sociologia, a sua importância se dá no domínio da transmissão de um aprendizado incorporado. Isto se deu entre o início dos anos 1970 até os anos 1990, no interior do sistema de pós-graduação brasileiro, antes que, com a consolidação dos doutorados nacionais, o sistema de bolsas de estágio doutoral "sanduíche" e as bolsas de pós-doutorado tenham proporcionado estágios nas instituições francesas, inclusive nos centros em que a influência de Bourdieu se fazia notar, aumentando, desde os anos 1990, as possibilidades de contato direto dos pesquisadores brasileiros de diversas instituições.

Isto não quer dizer que o uso de Bourdieu fosse unânime no Museu Nacional, longe disto; os efeitos de campo também se exercem neste caso e a vinculação com autores de referência é um dos diferenciadores de linhas de pesquisa e perspectivas diversificadas. Mas a sua apropriação entre os pesquisadores do campesinato e dos trabalhadores em geral, dos que lidam ou lidaram com pensamento social, antropologia da política e antropologia econômica é generalizada desde os anos 1970 e sua importância na formação das gerações seguintes é grande. ${ }^{26}$

Uma outra fonte histórica de divulgação da obra de Bourdieu no Brasil é o grupo de pesquisa criado por Sergio Miceli, sociólogo, ex-professor da Fundação Getulio Vargas de São Paulo (FGV-SP) e professor do Departamento de Sociologia da USP. Três anos mais novo que Moacir Palmeira, como ele Miceli também fez sua graduação na Escola de Sociologia da Pontifícia Universidade Católica do Rio de Janeiro (PUC-Rio), formando-se em 1967. Após um mestrado na USP, Miceli inscreveu-se no doutorado da EHESS sob a orientação de Bourdieu. Ele já havia entrado em contato anteriormente com o autor francês para organizar uma edição no Brasil de uma coletânea de seus artigos, que veio a ser A economia das trocas simbólicas, publicado pela editora Perspectiva em 1974. Neste livro, Miceli, em estreita colaboração com o autor na escolha dos artigos, apresentava ao público leitor brasileiro, em uma introdução do livro, artigos importantes de Bourdieu espalhados em revistas acadêmicas de difícil obtenção até para o público francês.

Quando Miceli foi ser seu orientando de doutorado na École (EHESS), Bourdieu já havia feito sua primeira estadia de longa duração nos Estados Unidos, na Universidade de Princeton (ano universitário 1972-1973). ${ }^{27}$ Diferentemente de Touraine e alguns colegas de sua geração, que foram aos EUA com bolsas no início dos anos 1950, como um aprendizado de início de carreira, Bourdieu foi numa situação de professor convidado. Já então era directeur d'études da EHESS, e já havia publicado, em sua coleção, Le sens commun na editora Minuit, autores de universidades norte-americanas como Erving Goffman (Asiles, 1968), Herbert Marcuse (Raison et révolution, 1968), Edward Sapir (Linguistique, 1967), dentre vários livros de autores franceses e internacionais. ${ }^{28}$ No ano mesmo de 1973, durante sua estadia em Princeton ou logo após seu 
retorno, foram publicados na mesma coleção outros dois livros de Goffman (La présentation de soi e Relations en public; Les rites d'interaction seria publicado no ano seguinte). Segundo David Swartz (1998: 26), Bourdieu já teria se encontrado pessoalmente com Goffman numa das curtas viagens aos Estados Unidos que fizera nos anos 1960 às universidades da Pensilvânia e de Princeton. Diferentemente da influência de Parsons, Merton e Lazarsfeld sobre o aprendizado dos jovens pesquisadores franceses dos anos 1950, Bourdieu, que fez seu aprendizado dos sociólogos (e antropólogos) norte-americanos lendo- os dentro da França, já tinha uma aversão aos setores dominantes daquela sociologia situada nas universidades de Harvard ou Columbia e simpatizava com as novas gerações formadas na tradição da chamada Escola de Chicago.

De fato, pode-se avaliar que nos cinco anos de diferença que separam Bourdieu de Touraine tenha havido tempo para uma relativa recuperação do campo acadêmico e técnico francês em relação ao mais imediato pós-guerra. Por exemplo, enquanto os jovens sociólogos franceses (entre os quais estava Touraine) iam aos Estados Unidos no início dos anos 1950 buscar uma formação nas técnicas estatísticas auxiliares, Bourdieu, no final dos anos 1950 e início dos 1960, iria buscar nos jovens (como ele) estatísticos do INSEE (o IBGE da França) em missão na Argélia os instrumentos para a feitura de um livro conjunto, Travail et travailleurs en Algérie, livro este que até hoje se mantém como referência para a colaboração autorreflexiva entre as duas disciplinas, livres do "fetichismo da estatística" que poderia rondar os sociólogos. ${ }^{29}$ Alguns destes mesmos colaboradores estatísticos irão colaborar mais adiante nas pesquisas do Centre de Sociologie Européenne que Bourdieu dirige, como nas pesquisas sobre a frequentação socialmente diferenciada dos museus europeus. Assim, tudo indica que Bourdieu tenha encontrado na sua formação em Filosofia na École Normale Supérieure os recursos para que pudesse enfrentar, como "autodidata", a literatura antropológica e sociológica de que se nutriu para analisar a realidade social argelina dos anos 1950 e 1960 que o fascinara. Tal formação havia sido feita na vertente de Filosofia da Ciência, cujos mestres eram Bachelard, Canguillem (seu orientador) e Vuillemin, dotando-o de instrumentos de epistemologia científica que o iriam acompanhar ao longo de sua trajetória. ${ }^{30}$ Este aprendizado lhe traria uma grade de leitura dos clássicos nas Ciências Sociais, como Marx, Durkheim e Weber, diferenciada da que vinha sendo feita nos centros dominantes da Sociologia. ${ }^{31}$ Sua leitura de Weber, central em seus textos sobre a transformação social na Argélia e, posteriormente, para a construção de sua noção de campo, distanciavam-no daquela que vinha sendo feita por Parsons e outros colaboradores nos Estados Unidos. ${ }^{32}$

Quando fez seu doutorado sob a orientação de Bourdieu entre 1975 e 1978, Miceli, como dissemos, já havia organizado com ele A economia das tro- 
cas simbólicas, e pôde beneficiar-se da ebulição em andamento no Centro de Sociologia Europeia com a fabricação do lançamento da revista Actes de la Recherche en Sciences Sociales. ${ }^{33}$

Remeto à breve descrição que havia feito da trajetória de Miceli em artigo anterior. ${ }^{34} \mathrm{Na}$ continuidade da descrição havia observado que Miceli teve que conquistar seu lugar na USP a partir de uma situação inicialmente desfavorável, com referência à hostilidade e aos preconceitos para com a sua proximidade de Bourdieu, em virtude da importação para São Paulo do contexto francês de suposta rivalidade com o grupo de Alain Touraine (Leite Lopes, 2003b). Aqui a própria consolidação da Sociologia da USP e sua excelência faziam com que houvesse uma resistência a novos autores outsiders. ${ }^{35}$

O ótimo artigo de Fernando Pinheiro Filho sobre a recepção de Bourdieu no Brasil (2009) vale-se de meu artigo anterior para trazer novas contribuições sobre o assunto. Ele argumenta que apesar de ter havido uma incorporação das obras de Bourdieu inicialmente entre uma parte dos antropólogos do Museu Nacional, a USP e seu entorno em São Paulo teriam as melhores condições para a recepção durável da obra de Bourdieu após sua introdução pelas iniciativas editoriais de Miceli e por seu trabalho de pesquisa e ensino próprios. O autor reitera a já clássica análise da prevalência das ciências sociais na USP desde os anos 1950 no cenário brasileiro, resultante da decisiva atividade das elites paulistas nas circunstâncias da revanche cultural à derrota de 1932 e diante de um Rio de Janeiro distrito federal cujas experiências universitárias são malsucedidas em face da instabilidade política que as permeavam (ver Miceli, 1989). Pinheiro Filho foi certamente levado a este raciocínio reagindo à confissão, no meu artigo, da perspectiva crítica que alimentava minha geração de antropólogos do campesinato e das classes trabalhadoras diante da produção da geração anterior de sociólogos do trabalho e, por extensão, do estilo estabelecido na sociologia uspiana. ${ }^{36}$ Isto apesar da nossa admiração nutrida por esta mesma escola, que passou, após 1964, a ser reprimida e ainda assim soube permanecer viva e transformadora, seja na universidade e nas instituições paralelas que criou, seja no exílio. Esta nossa ambiguidade nos levou a uma postura compreensiva que o instrumental sobre a sociologia da universidade e dos intelectuais de Bourdieu, dentre outras perspectivas, pode propiciar (ver Leite Lopes, Pessanha \& Ramalho, 2012). Talvez mais do que a disputa pela taça Roberto Gomes Pedrosa (o antigo torneio Rio-São Paulo de futebol que precedeu o Brasileirão dos anos 1970) acadêmica, se possa atentar para os fluxos de pesquisadores entre os dois centros, bem como seu transbordamento diversificado para múltiplos pontos na rede de pós-graduação e pesquisa que se formou no país desde os anos 1970 e se espraia significativamente até hoje. ${ }^{37}$ Se uma instituição como o CBPE, criada por Anísio Teixeira e sediada na capital, por exemplo, for examinada, se verá a conexão entre equipes formadas no Rio por Darcy Ribeiro 
(como se sabe, mineiro egresso da Escola de Sociologia e Política de São Paulo) e as equipes da USP e de egressos da ESP (como Oracy Nogueira e Juarez Brandão Lopes) que participavam dos projetos do Centro nos anos $1950 .{ }^{38}$ Não é desconectado desta rede que Roberto Cardoso de Oliveira, filósofo graduado pela USP, orientando de Florestan Fernandes, virá para o Rio de Janeiro e alguns anos depois de sua chegada irá fundar o PPGAS-MN em 1968, juntamente com David Maybury-Lewis e o apoio de Castro Faria.

Também no sentido inverso, há os que, formados na graduação do Rio de Janeiro, na Escola de Sociologia e Política da PUC-Rio e na Faculdade Nacional de Filosofia (FNFi), irão procurar a pós-graduação da USP e depois vão se fixar nas instituições universitárias de São Paulo. Sergio Miceli é um deles, formado pela Sociologia da PUC-Rio, dentre as gerações cariocas que procuravam com afinco a profissionalização em ciências sociais (desde a geração de Moacir Palmeira, Otávio Velho e Luiz Antonio Machado da Silva, graduada em 1964 - para me ater a alguns nomes - até as seguintes, de Miceli, Lygia Sigaud, Alice de Paiva Abreu, Celina Vargas do Amaral Peixoto, Paulo Sergio Pinheiro, todos da PUC, e Aspásia Camargo, Sergio Silva, Gilberto Velho, Yvonne Maggie, e outros, da $\mathrm{FNFi}^{39}$ ). É no contexto dos círculos de jovens intelectuais cariocas, entre a sociologia e o teatro, que Miceli pôde se permitir a leitura deste autor desconhecido que era Bourdieu, que escrevia sobre campo intelectual e sociologia da cultura..$^{40} \mathrm{E}$ com seus ex-colegas cariocas, em particular com sua amiga de longa data, Lygia Sigaud, pôde Miceli compartilhar desde cedo (e desde sempre) suas leituras de Bourdieu. ${ }^{41}$

Assim, com base nesta sua acumulação prévia não uspiana de capital cultural, Miceli já foi construindo seu caminho na pós-graduação da USP de forma independente, tanto do leque de pesquisas que ainda coordenava Florestan Fernandes e que lhe fora oferecido em 1968, bem como dos seus orientadores, Marialice Forachi e Leôncio Martins Rodrigues (os detalhes em entrevista com Miceli estão na matéria da revista Piauí, já referida). A acolhida que lhe proporcionou Leôncio no doutorado, mesmo não sendo a área de pesquisa de Miceli a de sua especialidade, é ilustrativa do grau de abertura existente na USP para com um aluno de excelente desempenho. No entanto, sua inserção profissional na FGV entre 1971, logo após seu mestrado, até 1986, onde foi professor de sociologia, editor da Revista de Administração de Empresas, e chefe do Núcleo de Pesquisas e Publicações, lhe deu mais liberdade ${ }^{42}$ para levar a cabo sua pesquisa de doutorado, fazendo-o no exterior, entre 1974 e 1978 sob a orientação de Bourdieu (paralelamente à sua feitura na USP, entre 1973 e 1978, sob a orientação de Leôncio Martins Rodrigues), bem como, posteriormente, fazer sua pesquisa de livre-docência sobre o campo eclesiástico brasileiro, que defende na Universidade Estadual de Campinas (UNICAMP) em 1986. Em 1989 entra para o Departamento de Sociologia da USP e em 1992 é professor titular. 
Assim sua trajetória parece indicar que a plena legitimação do uso de Bourdieu na Sociologia da USP, com a incorporação no corpo professoral de seu talvez único ex-orientando brasileiro de doutorado e responsável por muitas das mais importantes traduções daquele autor no Brasil, é relativamente recente; e se dá depois que tanto Miceli já era renomado nacionalmente, quanto Bourdieu o era internacionalmente. ${ }^{43}$ Enquanto isto, outros colegas de universidades em São Paulo, como Letícia Canêdo, na Educação da UNICAMP, ou Roberto Grün, sociólogo na Engenharia de Produção da Universidade Federal de São Carlos, desenvolveram contatos constantes com o centro de pesquisa e a equipe em torno de Bourdieu desde o início dos anos 1990 através de períodos de pós-doutorado e convênios internacionais.

Uma outra trajetória em trânsito não somente entre o Rio e São Paulo, mas também entre Touraine e Bourdieu, é a de Maria Andrea Loyola. Andrea acompanhou desde 1961 os cursos de especialização dados por Roberto Cardoso de Oliveira no Museu Nacional, foi estagiária de Castro Faria no Setor de Arqueologia e foi da primeira turma do mestrado do PPGAS-MN-UFRJ criado em 1968. Na ocasião era professora de Ciências Sociais na Universidade Federal de Juiz de Fora (onde havia concluído sua graduação em 1960) desde 1965 , quando teve sua carreira interrompida por sua aposentadoria precoce pelo AI-5, em dezembro de 1968. Defendeu sua dissertação em 1972, Trabalho e modernização da indústria têxtil, com base em material empírico do polo industrial de Juiz de Fora, orientada por Leôncio Martins Rodrigues da USP (orientador externo no PPGAS-MN). No PPGAS-MN fez assim uma ponte com a Sociologia da USP. Foi orientada no doutorado por Alain Touraine, com a tese Les ouvriers et le populisme (Universidade de Nanterre-Paris X) em 1973. Entre 1974 e 1985 foi pesquisadora do Centro Brasileiro de Análise e Planejamento (CEBRAP) e professora de Sociologia na PUC-SP (quando orientou a dissertação de Roberto Grün sobre os bancários de São Paulo). Entre 1986 e 1999 fez parte do Núcleo de Estudos da População da UNICAMP. Desde 1982 se vinculou à Universidade do Estado do Rio de Janeiro (UERJ), ao Instituto de Medicina Social, onde desenvolveu pesquisas sobre usos sociais do corpo e da sexualidade. Na UERJ foi sub-reitora de pesquisa e pós-graduação nos anos 1990 e foi Coordenadora da Coordenação de Aperfeiçoamento de Pessoal de Nível Superior (CAPES). Após seu doutorado com Touraine, Andrea se aproximou do centro de Bourdieu desde meados dos anos 1970, onde fez estágios de pós-doutorado em 1980-1981 e em 1995 e esteve sempre presente através de intercâmbios institucionais. Em 1982 publicou o artigo "Cure des corps et cure des âmes. Les rapports entre les medicines et les religions dans la banlieue de Rio" na revista Actes de la Recherche en Sciences Sociales (1982), que serviu de base para o livro Médicos e curandeiros: conflito social e saúde (1984), tradução de: L'éspirit et le corps: des thérapeutiques populaires dans la banlieue de Rio (1983). Além disso, em 2001 dirigiu o vídeo "Pierre Bourdieu. Série Pensa- 
mento Contemporâneo", pela UTV da UERJ, entrevista que foi reaproveitada no interior do filme de Pierre Carles, La sociologie est un sport de combat e depois foi transcrita e editada pela editora da UERJ em 2002.

Os fluxos de pesquisadores entre centros e pensamentos de escola regionais são assim mais frequentes e intensos do que habitualmente se destaca, como parecem indicar muitas trajetórias acadêmicas. Também o deslocamento de Afrânio Garcia Jr. do Museu Nacional, onde fez o mestrado e o doutorado com pesquisas sobre o campesinato sob a orientação de Moacir Palmeira, para ser professor na EHESS de Paris desde 1996, estando inserido ao mesmo tempo no centro de Bourdieu e até recentemente na direção do Centre de Recherches sur le Brésil Contemporain (CRBC), contribuiu para organizar um ecumenismo produtivo das diferentes procedências de doutorandos, doutorandos-sanduíche, pós-doutorandos e pesquisadores sênior de todo o Brasil nos seus intercâmbios com centros franceses. Sendo ele frequentemente o supervisor do estágio de doutorado-sanduíche ou o anfitrião de pós-doc, ou do intercâmbio de pesquisador visitante, ou ainda chamado por supervisores de outros centros franceses a auxiliar no trabalho de supervisão dos estágios, Afrânio Garcia Jr. tornou-se, nos anos 1990 e 2000, um polo-chave no intercâmbio entre pesquisadores brasileiros e franceses em ciências sociais. ${ }^{44}$ Como integrante do centro de Bourdieu (para efeitos do que estamos tratando neste artigo), e relacionado com a constelação de pesquisadores de outros centros que passaram por tal orientação (dissidentes ou não), sua posição-chave no intercâmbio repercute na qualidade da apropriação desta escola de pensamento no campo das ciências sociais brasileiras (embora seu trabalho neste intercâmbio transcenda esta escola, mesmo tomada aqui em sentido amplo).

Pode-se mencionar, ainda, a relação de pesquisa estabelecida por Lygia Sigaud com pesquisadores da École Normale Supérieure de Paris (ENS, ilustrativos da constelação aludida logo acima), instituição onde foi professora visitante, na pesquisa coletiva realizada sobre os acampamentos de trabalhadores rurais em Pernambuco no final dos anos 1990, envolvendo professores e alunos do PPGAS-MN-UFRJ e da ENS.

Deve-se dar um lugar de destaque também, na organização da circulação entre pesquisadores franceses e brasileiros, a Monique de Saint-Martin, que foi diretora do Centre de Sociologie de l'Éducation et de la Culture da EHESS até o final dos anos 1990. Ela veio ao Brasil em 1976 a pedido de Bourdieu para conhecer de perto os grupos de pesquisa já em contato com o seu centro e aprofundar as relações com eles, bem como conhecer novos. Por mais de vinte anos foi uma coordenadora importante da rede de pesquisadores internacionais que aquele centro constituiu. ${ }^{45}$ Se Bourdieu pôde evitar sua vinda ao Brasil mesmo tendo crescentes convites de pesquisadores brasileiros que eram dos mais numerosos grupos nacionais a frequentarem o seu centro, 
em parte isto se deveu à dedicação de Saint-Martin que realizou as viagens necessárias ao país. (Quando provavelmente passou a considerar a vinda ao Brasil como iminente, estava em seus últimos anos e a manifestação repentina da doença que o acometeu impediu esta possibilidade.) Monique manteve relações constantes com os pesquisadores brasileiros na França e segue vindo ao Brasil para encontros a convite de pesquisadores brasileiros.

\section{COMENTÁRIOS FINAIS}

A apropriação diferenciada da obra, do pensamento de escola e dos instrumentos de pesquisa de autores tais como Touraine e Bourdieu pelo campo brasileiro de ciências sociais é, como sabemos e como procuramos mostrar, especificada historicamente. As diferenças temporais entre as trajetórias dos dois autores produz um diálogo que atinge diferentes gerações. A abrangência temática, bem como os instrumentos de trabalho privilegiados pelos autores também circunscrevem a sua receptividade por diferentes grupos de pesquisadores em outros campos nacionais. Por outro lado, vemos também como está em jogo na circulação de ideias e pesquisadores não somente a relação entre os campos das ciências sociais francês e brasileiro, mas também a relação com outros campos dominantes ao longo do tempo, como, por exemplo, a relação diferencial dos autores com o campo norte-americano.

A bagagem acumulada de sociologia industrial e do trabalho por parte de Touraine fez com que fosse procurado pela sociologia da USP no momento mesmo em que as pesquisas sobre o fenômeno industrial de São Paulo eclodiam. Ele se encontrou com pesquisadores como Azis Simão e Juarez Brandão Lopes, que já tinham acumulado investigações anteriores sobre trabalhadores industriais no Brasil, e incentivou a conformação institucional de um centro de pesquisa específico para este fim reunindo novos pesquisadores (o CESIT). Graças à missão para a qual foi convidado pela USP em 1960 manteve relações permanentes com alguns dos discípulos de Florestan Fernandes. Com a mudança de foco da sociologia industrial para a sociologia dos movimentos sociais, Touraine também atraiu novas gerações de orientados e pesquisadores brasileiros e latino-americanos. Por sua ligação profissional e afetiva com o Chile, e por ter diretamente estudado temáticas latino-americanas, sempre foi um autor privilegiado nos círculos sociológicos locais (além de solidário nos exílios dos pesquisadores latino-americanos nos períodos de ditaduras locais).

Já a apropriação de Bourdieu incide sobre gerações subsequentes, inicialmente trazida de forma precoce por bolsistas que frequentaram seus cursos poucos anos depois de sua titularidade na EHESS, e que fizeram com que sua recepção por antropólogos e sociólogos brasileiros pudesse ser próxima 
à produção dos seus primeiros escritos e houvesse um acompanhamento do decorrer de sua obra. De forma que ao ser traduzido e ter adquirido renome nos anos 1990 nos países anglo-saxônicos dominantes no campo das ciências sociais, já era bem conhecido nos círculos especializados brasileiros. Seus estudos sobre o campesinato cabila (e francês) e os trabalhadores argelinos atraiu os antropólogos brasileiros sequiosos de novos instrumentos para a análise das classes populares. Por outro lado, suas análises críticas sobre os intelectuais e a escola forneceram ferramentas reflexivas para o autoconhecimento sobre os produtores de conhecimento no país, por parte de novas gerações de cientistas sociais. As antecipações de tendências que Bourdieu fez desde cedo ao longo de sua carreira fizeram parte destas ferramentas: o uso crítico simultâneo da estatística e da etnografia; a militância científica do empreendimento de conhecimento etnográfico, mesmo nas situações extremas de dominação social, como na situação de guerra na Argélia; a antecipação da crise escolar e universitária na França nos anos 1960; o uso cruzado da etnografia das sociedades tradicionais em transformação e da sociologia da dominação cultural das sociedades ditas complexas na superação dos ganhos de conhecimento da revolução estruturalista por uma concepção histórica de uma sociologia da prática. Dentre o conjunto de autores que surgiram nos anos 1960 fornecendo ferramentas conceituais inovadoras para as gerações das décadas seguintes, como Foucault ou E. P. Thompson, Bourdieu se destaca pelas frentes diversificadas em que tais antecipações no entendimento da direção em que ocorriam as transformações sociais em curso se deram. No momento em que as ciências sociais brasileiras se consolidavam de forma significativa com o crescimento das pós-graduações a partir dos anos 1970, tal instrumental de antecipações forneciam munição, juntamente com outras tradições intelectuais coerentemente apropriadas, para a crítica e para o resgate das contribuições das gerações pioneiras anteriores.

Por outro lado, a apropriação precoce dos estudos de Bourdieu sobre o campesinato e os trabalhadores argelinos por parte dos antropólogos do campesinato e das classes trabalhadoras brasileiras previne-os de estranhar a suposta guinada de Bourdieu nos anos 1990, com a publicação do livro A miséria do mundo e com a proeminência de intelectual público adquirida como participante de movimentos sociais contra o neoliberalismo triunfante. Trata-se, após um percurso de estudos em direção ao estudo das dominações simbólicas e culturais, privilegiando os campos dos dominantes - sistema escolar, nobreza de estado, o campo político, o campo cultural, o campo intelectual, a formação do Estado - de uma nova ênfase nos efeitos sofridos pelas classes e grupos sociais dominadas. Não foi por acaso que Bourdieu tinha em sua equipe desde sempre pesquisadores como Abdelmalek Sayad, estudioso da imigração magrebina na França, ou como Michel Pialoux, investigador da classe operária francesa. Uma atualização, com vistas ao estudo 
dos novos proletários franceses dos anos 2000, dos achados de pesquisa iniciados na Argélia do início dos anos 1960 pôde assim ser feita, como se observa em capítulos do livro quase-testamento em que se constitui o Meditações pascalianas. E restitui as contribuições menos evidenciadas de Bourdieu e seus colaboradores sobre os estudos das classes dominadas, ao lado de seus resultados e obras sobre os polos dominantes dos campos sociais.

Recebido em 02/04/13|Aprovado em 04/05/13

José Sergio Leite Lopes é o atual Diretor do Colégio Brasileiro de Altos Estudos da Universidade Federal do Rio de Janeiro (UFRJ), e é um dos coordenadores do Núcleo de Antropologia do Trabalho, estudos biográficos e de trajetória (NuAT) do Programa de Pós-Graduação em Antropologia Social (PPGAS) do Museu Nacional/UFRJ, onde fez seus mestrado (1975) e doutorado (1986). É autor de O vapor do diabo (1976); de A tecelagem dos conflitos (1988) e de A ambientalização dos conflitos sociais (2004). 


\section{NOTAS}

1 Aqui se tratará de obras no sentido amplo, incluindo a sua importância na constituição de redes de pesquisadores nacionais e internacionais, vistas da perspectiva da recepção nas ciências sociais brasileiras.

2 "Pierre Bourdieu et le renouveau des enquêtes ethnologiques et sociologiques au Brésil" (2003a). Este artigo foi republicado com algumas modificações em Dubois, Durand \& Wikin (2005). Em português, na Revista de Cultura Vozes (2003b). A versão brasileira do texto é um pouco maior.

3 "C'est un choc dans la mesure où notre univers intellectuel à tous, le mien particulièrement, est un monde qui s'organisait, non pas complètement mais en partie, par rapport à Bourdieu. Il était une référence positive ou négative indispensable. Il avait grossi comme un arbre qui pousse ses racines et ses feuilles et couvrait un domaine énorme de l'opinion. Le fait que mes orientations, mon travail ont toujours été et de plus en plus opposés aux siens, me donne la liberté de dire que son oeuvre est considérable. [...] Quand je regarde ses positions au cours des années, rétrospectivement, je me sens d'accord avec $90 \%$ d'entre elles, même si nous nous sommes heurtés sur la grève de 1995. Il est du côté des déterminismes sociaux, je suis du côté de la liberté, mais les deux faces de la sociologie ne peuvent vivre l'une sans l'autre. Et j'ai le sentiment qu'une partie importante de ma vie a été, sans parler, un dialogue avec lui, comme cela fut le cas avec les sociologues américains ou avec Althusser...". Libération, 25/1/2002.

4 Acabei achando uma referência na nota de rodapé da p. 27 do livro Culture and power: the sociology of Pierre Bourdieu, de David Swartz, onde é dito que os votos de Raymond Aron (cadeira de "Sociologie de la civilisation moderne", 1970-1982), Lévi-Strauss (cadeira de "Anthropologie sociale", 1959-1978) e Braudel (cadeira de "Civilisation moderne”, 1949-1972) teriam sido decisivos na eleição de Bourdieu para a cadeira de Sociologia do Collège de France, que vinha sendo disputada com Touraine.

5 “C'était peut-être par l'intermédiaire d'ailleurs de l'Association Internationale de Sociologie (AIS) dont Fried- 
man était le président, je ne me rappelle plus, mais la même demande finalement m'a été faite par la USP et donc, je suis venu; et alors, c'est amusant parce que je suis venu enseigner dans le cadre de la 'Cadeira 2', c'est-à dire Fernando de Azevedo... Et au bout de deux mois ou quelque chose comme ça, on m'a demandé de préciser mes projets, de faire des propositions et j'ai dit: 'Et bien, je crois qu'il faut faire un centre de sociologie du travail et je propose que le directeur en soit Fernando Henrique Cardoso'. Scandale! Parce que c'était l'autre cadeira, c'était la Cadeira 1! Alors j'ai été considéré comme un traître; alors, j'ai fait comme tous les traîtres: je suis passé chez l'ennemi et donc je suis resté très ami de Fernando Henrique, d'Octavio Ianni, de ces gens-là..." (Entrevista com Alain Touraine, concedida ao autor em fevereiro de 1994).

6 Os projetos iniciais que davam surgimento ao CESIT estão em Fernandes, A sociologia numa era de revolução social (1976): cap. 10 "Economia e sociedade no Brasil: análise sociológica do subdesenvolvimento", e cap. 11 "A empresa industrial em São Paulo; projeto de estudo", p. 314-358. Ver também Arruda \& Garcia (2003: cap. 9).

7 Dentre os orientados de Touraine figuram, dentre outros, sociólogos com importantes contribuições tais como, Andrea Loyola (Les ouvriers et le populisme, Universidade de Nanterre-Paris X, 1973); Aspásia Camargo (Brésil, Nordest: mouvements paysans et crise populiste, EHESS, 1973); Ilse Scherrer (Le syndicat et le changement de la société agraire dans le Rio Grande do Sul, Universidade de Nanterre-Paris-X, 1973); Décio Saes (Classe moyenne et système politique au Brésil, EHESS, 1974); e Tom Dwyer (Une conception sociologique des accidents du travail, EHESS, 1978). Touraine teria orientado nove teses sobre o Brasil. Dentre os professores na França que mais orientaram teses "sobre o Brasil" até 1999, estão: Fréderic Mauro (História, 30 teses), Michel Rochefort (Geografia, 25), Ignacy Sachs (Economia, Ecologia, 22), Pierre Salama (Economia, 21), Michel Mafesoli (Sociologia, 15), Pierre Monbeig (Geografia, 9), Katia Mattoso (História, 9). Ver Sabóia (2000).

8 "Mais vous savez, quand on est Européen, il y a deux manières d'aborder l'Amérique Latine: il y a la manière Bastide, protestant, Cévenol, austère: alors il cherche les 
tambours, la sexualité, l'Amérique chaude. Moi je suis aussi du genre puritain mais j'ai toujours eu, même exagérément, horreur du tropical parce que je trouvais ça colonialiste. Alors, je voulais traiter les Latino-Américains dans des rapports d'égalité, ce qui manquait d'imagination par beaucoup de côtés mais pour moi, mon Amérique Latine, a toujours été une Amérique Latine très sérieuse, très travailleuse et cela n'est pas par hasard que je suis un Chiléno-Brésilien" (Entrevista com Alain Touraine, concedida ao autor em fevereiro de 1994).

9 “C'était un programe de formation mais l'idée c'était quand même de faire de la formation de chercheur et par conséquent, il y avait une partie de formation proprement dite, d'enseignement si je puis dire et il y avait une partie 'exécution d'une recherche', une véritable recherche" (Entrevista com Jean Daniel Reynaud, concedida ao autor em fevereiro de 1992).

10 Inicialmente este trabalho foi sua dissertação na École Normale Superieure, orientada pelo historiador Ernest Labrousse. Tornou-se uma publicação pelo CES na editora do CNRS em 1955, após acrescentar um trabalho de observação local estimulado por Friedmann sobre as consequências das atitudes operárias da evolução técnica de setores da siderurgia como a laminação. Ver Touraine (1955).

11 “On peut dire que la recherche avait été très largement dessinée et conçue par Touraine, que c'est moi qui ai réalisé le travail sur le terrain et que le dépouillement a été fait par Brams et Di Tella puisque c'est très largement lui qui a rédigé les résultats. Le problème posé était simple: bon, il est vrai que c'était un peu bizarre comme division des tâches mais cela peut s'expliquer aussi du fait que entre nous trois, il n'y avait pas beaucoup de problèmes pour poser les choses dans les mêmes termes. Donc cela avait du sens de faire une même étude successivement à plusieurs" (Entrevista com Jean Daniel Reynaud, concedida ao autor em fevereiro de 1992).

12 "Le thème de départ était simple: c'était, en prenant deux régions géographiquement très proches puisque Lota comme Huatchipato sont de la même province du Chili... Concepción. Et bien c'est le Sud, ce n'est pas le Grand Sud, si 
quand même... C'est à 650 kilomètres de Santiago! Et, il y avait d'une part, l'índustrie la plus traditionnelle: le charbon et, d'autre part, une des premières (je crois que c'était la seconde) industrie sidérurgique d'Amérique Latine, Huatchipato. Huatchipato qui est en fait dans la banlieue de Concepción. Et donc, l'idée très simple, c'était l'idée de comprendre ce que voulait dire 'modernisation'.

Est-ce qu'on pouvait, en comparant ces deux situations très proches géographiquement qui, finalement, recrutaient leurs salariés sinon tout à fait de la même manière, du moins dans la même zone, est-ce qu'on pouvait se demander ce qui changeait avec la modernisation et... 'modernisation' ne semble pas le mot que nous aurions employé à cette date. A cette date, le mot était 'développement' mais, en même temps, notre idée était bien de prendre un petit peu de distance par rapport à l'idée strictement économique de développement. C'est nous demander dans quelle mesure un développement économique reposait aussi sur des transformations des relations sociales et on aurait dit, à cette date, des 'attitudes'. On s'adonnait donc au travail de terrain avec un nombre d'enquêtés relativement élevé" (Entrevista com Jean Daniel Reynaud, concedida ao autor em fevereiro de 1992, grifos meus).

13 A notar que este tipo de comparação, por coincidência também entre os mineiros do carvão e os novos metalúrgicos do Vale do Rhur, é utilizada no final dos anos 1970, na análise histórica do período pré-nazista na Alemanha feita por Barrington Moore Jr. no livro Injustiça; as origens sociais da obediência e da revolta ([1978] 1987: cap. 7). A análise, que se beneficia da abertura de perspectivas feita por E. P. Thompson desde 1963, mostra como as concepções tradicionais dos mineiros lhes beneficiavam na compreensão das mudanças sofridas pelos trabalhadores, proporcionando-lhes um protagonismo no movimento social que os novos metalúrgicos não apresentavam.

14 O capítulo "O ajustamento do trabalhador à indústria: mobilidade social e motivação" (p. 22-93), retoma texto escrito em torno de 1960 como folheto para o Instituto de Economia e Administração da USP e artigo na revista Educação e Sociedade do CBPE. 
15 A divisão do trabalho na equipe de pesquisa é assim explicada: "Cette enquête [...] a été menée sous la direction de A. Touraine par O. Ragazzi qui a redigé le questionnaire à partir de celui qui était utilisé par l'enquête sur la representation ouvrière du travail et de la société (dirigée para A. Touraine), recueilli les documents, classé les réponses. Le rapport d'enquête a été rédigé en collaboration par A. Touraine et R. Boudon, ancien élève de l'École Normale Supérieure, agrégé de philosophie. L'introduction et la conclusion sont de A. Touraine" (note, p. 15). Segundo Lucie Tanguy, “Boudon rappelle qu'Alain Touraine lui a mis le pied à l'étrier [lhe deu a primeira ajuda] 'en lui proposant d'analyser la pile de tableaux tirés de son enquête sur les ouvriers d'origine agricole' et ainsi facilité son entrée au CNRS où il put réaliser sa thèse sur L'analyse mathématique des faits sociaux dans des conditions confortables" (Tanguy, 2011: 135, nota 5).

16 Como, por exemplo, nesta apreciação crítica retrospectiva de Touraine feita sobre o que encontrou durante sua estadia de 1952 em Harvard, citada em Chapoulie (1991: 348): "Um mundo intelectual muito refinado, mas onde falta, aos meus olhos, coragem, de quem já não ousa olhar a sociedade frente a frente [regarder la société en face], contentando-se de a recobrir dos falsos esplendores de teorias reconfortantes. O triunfo do funcionalismo desta época não pode se compreender sem esta grande satisfação de si, esta ausência de crítica sobre a sociedade americana que se explicava pela formidável potência deste país e sua força de integração e de luta contra os desviantes neste período de Guerra Fria" (ver Touraine, 1977: 66-67).

17 "Monsieur Touraine est un esprit brillant et certainement une des personnalités de sa genération au CES. Toutefois nous l'avons mis en garde contre une propention trop marquée à l'esprit de système, aux généralisations un peu hâtives et lui avons plusieurs fois recommandé de ne pas clore prématurément une phase d'observation [...] concrète $[\ldots]$.....] son premier objectif devait être la mise au point définitive de son rapport d'enquête sur la Régie Renault qui doit être publié dans les 'Travaux du CES'." (Dossier Alain Touraine, Archives CNRS, 910024 DPC, 1953-54, rapporteur, Friedmann). Ver Tanguy (2011: 134). 
18 Tanguy acrescenta "Allusion au séjour fait par Touraine aux États-Unis (bourse Rockefeller de septembre 1952 à septembre 1953), dont Friedmann reticent: 'Harvard où il etudie les problèmes de methode de la sociologie américaine; ensuite dans differrentes universities dont les recherches l'intéressent directement en insistant tot particulièrement sur les ressources du Bureau of applied social research de Columbia University à New York.'" (Tanguy, 2011: 134, nota 4).

19 Touraine também esteve na Argentina em seguida à sua estadia no Chile, onde fez contatos com Gino Germani e outros sociólogos argentinos. Estabeleceu uma forte colaboração posteriormente com Silvia Sigal.

20 Dentre estes riscos se situa a defasagem entre a interpretação teórica e os dados empíricos construídos. Touraine enfrentou problemas desta ordem quando de sua defesa de tese de doutorado na universidade de Paris, sobre o texto que depois seria publicado como Sociologie de l'action, a partir da arguição de Raymond Aron (ver em suas memórias, Aron, 1983, p. 347-348, citação reproduzida em http://fr.wikipedia.org/wiki/Alain_Touraine), que acabou repercutindo sobre a severidade dos outros arguidores e sobre o candidato, e que consistia na crítica do uso inadequado de categorias filosóficas que se descolariam do seu material sociológico: "je reprochai à Touraine de se lancer dans des analyses plus philosophiques que sociologiques sans la maîtrise des concepts, sans la formation du philosophe." Difícil dizer a que ponto os rumores sobre esta defesa de tese tenham contribuído para reforçar a decisão de Bourdieu de não fazer a sua própria tese de doutorado, afinal fundada na recusa de Aron, que seria seu diretor de tese, à proposta de Bourdieu de fazê-la baseada nos seus materiais argelinos (de Travail et travailleurs en Algérie e Le déracinement). Aron teria dito: "Ce n'est pas digne de vous" (supondo talvez que o objeto deveria ser mais nobre ou tratado de forma mais filosófica, formação esta possuída por Bourdieu). Parte do que seria sua tese foi incorporado em Esquisse d'une théorie de la pratique, de 1972 (ver Bourdieu, 2004, p. 49-50). Já Sociologie de l'action, quando publicado como livro recebeu uma resenha crítica na Revue Française de Sociologie, reunindo de forma 
inusitada o colega de Touraine, Jean Daniel Réynaud e Bourdieu (1966: 508-517), logo respondida na mesma revista (Touraine, 1966: 518-527).

21 Assinale-se que a banca da tese de Palmeira foi constituída por François Bourricaud (orientador, fez estudos no Peru, indicado por Pierre Monbeig, que recebeu inicialmente o bolsista brasileiro com bolsa francesa), Touraine e Frederic Mauro, historiador brasilianista. Palmeira solicitou a presença de Bourdieu na banca mas não foi atendido, tendo o orientador aparentemente preferido uma banca latino-americanista. Quanto ao curso aludido, ver no site do PPGAS-MN < http://ppgasmuseunacional.web565. kinghost.net/cursos_ant.html> o curso: Estrutura Social do Brasil (Avaliação de Modelos) (AS-205), Prof. Moacir Gracindo Soares Palmeira, $2^{\circ}$ Período Letivo de 1970, 3 créditos. Os textos de Bourdieu, dentre outros autores, eram: Pierre Bourdieu, Champ intellectuel et projet créateur, Les Temps Modernes, 1966, 246, nov., p. 865-906 (tradução brasileira: Campo intelectual e projeto criador. In: Jean Pouillon et al. (orgs.). Problemas do estruturalismo. Rio de Janeiro: Zahar, 1968: 105-145); Pierre Bourdieu et al., Le métier du sociologue, $1^{\text {a }}$ parte (La rupture, caps. 1, 2, 3 e 4: 35-46; $1^{\text {a }}$ parte, caps. 5, 6 e 7, e Conclusions: 103-113, esp. p. 107-109, "L'enracinement social du sociologue"; Pierre Bourdieu \& Jean-Claude Passeron, Sociology and philosophy in France since 1945. Death and ressurection of a philosophy without subject, Social Research, 1967, 34, 1, Spring, p. 162-212.

22 Calhoun, "Centralité du social et possibilité de la politique" (2005: 225-256). No mesmo livro estão meu artigo anteriormente citado, "Pierre Bourdieu et le renouveau des enquêtes ethnologiques et sociologiques au Brésil" (2005: 103-111), e as considerações finais de Bourdieu, "Secouez un peu vos structures!” (2005: 325-341) no simpósio de julho de 2001 que serviu de base ao livro.

23 Tal é o caso das dissertações e teses de Lygia Sigaud (1979a e 1979b), de Afrânio Garcia Jr. (1982 e 1989), de Beatriz Heredia (1982 e 1989), de Rosilene Alvim (1974 e 1997), de Marie France Garcia-Parpet (1977 e 1984), de Alfredo Wagner de Almeida (1979 e 1993), Eliane Cantarino (1977 e 1988), Leilah Landim (1978 e 1993), Doris Rinaldi (1978), 
Regina Novaes (1978 e 1997), e alcançando as gerações seguintes.

24 Ver, em particular, a concepção de "situações-tipo" e a parte de metodologia em Palmeira et al. (1977). Ver também a apreciação sobre os efeitos deste projeto em Garcia Jr. (2011).

25 Por exemplo, ver Palmeira (1994); Sigaud (2008); Leite Lopes (2009); Garcia Jr. (2011).

26 Para uma análise da história da criação do PPGAS-MN-UFRJ, ver Garcia Jr. (2009).

27 No registro dos professores convidados que passaram pelo Institute for Advanced Studies, School of Social Sciences de Princeton, Bourdieu aparece sob o tema de pesquisa "Economia dos Bens Simbólicos": IAS-SSS -Princeton - Pierre Bourdieu - 1972-73 - SOC - Economy of Symbolic Goods.(Ver, por ordem alfabética, em <http://www.sss.ias. edu/people/past-scholars>).

28 Ver relação de livros na coleção Le sens commun, da Editora Minuit, cujo diretor era Bourdieu até o início dos anos 1990, em <http://www.leseditionsdeminuit.com/f/index. php? sp=coll\&collection_id $=49>$.

29 Garcia-Parpet (2003) analisa esta relação de Bourdieu com os estatísticos na Argélia.

30 Como se sabe, uma exibição desta maestria no manejo dos instrumentos de epistemologia científica aparece no trabalho em conjunto com Passeron e Chamboredon, Le métier du sociologue ([1968] 1983), todos formados nesta linha de filosofia da ciência na École Normale Supérieure.

31 Ver, por exemplo, o artigo "Gênese e estrutura do campo religioso" (Bourdieu, 1974: 27-78), incluído em A economia das trocas simbólicas.

32 Para consultar os estudos sobre a trajetória e as posições no campo intelectual de Weber, estudos estimulados por Bourdieu, ver Pollak (1996a, 1996b) e Kalinowski (2005).

33 Para uma extensa reflexão sobre este período, ver o livro de Boltanski (2008). Para uma reflexão sobre um período anterior do Centro, ver Delsaut (2005b) e uma visão mais geral em "Entrevista de Pierre Bourdieu com Yvette Delsaut: sobre o espírito da pesquisa" (2005a). 
34 "Miceli fez seus estudos de graduação de sociologia na Universidade Católica do Rio [... formando-se em 1967]. Fez a sua dissertação de mestrado na Universidade de São Paulo sobre um programa de auditório de televisão, sobre a cultura de massa; e seu doutorado foi feito ao mesmo tempo na USP, sob a direção de Leôncio Martins Rodrigues, sociólogo do trabalho da escola de São Paulo, e na EHESS, sob a direção de Bourdieu. Sua tese sobre os 'intelectuais e as elites dirigentes no Brasil' entre 1920 e 1945 foi construída enquanto estava na EHESS, no seminário de Bourdieu. Ele reuniu um grande acervo de trajetórias de intelectuais (principalmente escritores) mostrando como fizeram uma reconversão na vida intelectual a partir da decadência econômica de sua família de origem. A partir dos relatos autobiográficos, bem como de decretos e despachos de nomeação no Jornal Oficial, desvenda a cons trução de redes de capital social que ligam os intelectuais e os membros das elites políticas e econômicas. Analisa a relação entre os escritores e o Estado, ponto de chegada desses intelectuais, a partir de um movimento de reconversão, através da universidade, das elites em decadência para as novas profissões estatais (o aparelho burocrático estava em plena construção entre os anos 1920 e 1940). Em seguida estuda, através de métodos e acervos de dados semelhantes, o campo dos bispos; coordena estudos sobre a história das ciências sociais no país e, finalmente, se volta para o campo das belas artes e da pintura". Ver Leite Lopes (2003b: 11).

35 Posso remeter aqui à reportagem de Brian de Assis, "A invenção do intelectual”, na revista Piauí (2011, 62: 11): “De acordo com Maria Arminda [Arruda, colega de Miceli no Departamento de Sociologia] a tese de doutorado de Sergio é um marco nas Ciências Sociais brasileiras. Não somente pela apresentação de um novo jeito de ver a intelectualidade brasileira, mas pela coragem de Miceli em usar a referência de Pierre Bourdieu em um meio pouco receptivo ao autor francês dentro da Universidade de São Paulo".

Disponível em <http://www.scribd.com/doc/88791281/A-Invencao-do-Intelectual-vida-e-obra-do-sociologo-brasileiro-Sergio-Miceli>. Acesso em 1 maio 2013.

36 Ver, por exemplo, a perspectiva do meu artigo "Sobre os trabalhadores da grande indústria na pequena cidade: 
crítica e resgate da Crise do Brasil arcaico" (1987) e do de Rosilene Alvim, "Família e operários de origem camponesa: uma leitura da 'Crise do Brasil arcaico'” (1987), além da Introdução do livro Cultura e identidade operária (ver Leite Lopes, 1987).

37 A tal ponto que hoje o Projeto Nova Cartografia Social da Amazônia, coordenado por Alfredo Wagner de Almeida, e associado a pós-graduações na UFAM, UEAM e UFMA, é uma poderosa equipe de pesquisadores que utiliza com perícia as ferramentas calibradas por Bourdieu (dentre outras) no contexto dos conflitos territoriais e dos movimentos sociais de populações tradicionais em várias partes do país.

38 Ver o contexto do livro Crise do Brasil arcaico, de Juarez Brandão Lopes, assim como o depoimento na sessão "Conversa com o Autor", da ANPOCS. Ver também Marianni (1982). Dentre as pesquisadoras recrutadas pela equipe do CBPE estavam Maria Laís Mousinho Guidi (também assistente de Manuel Diegues Jr. na antropologia da PUC-Rio), Josildete Consorte e Alzira Abreu. Também a inclusão de Florestan Fernandes no suporte acadêmico ao Instituto de Ciências Sociais da Universidade do Brasil no início dos anos 1960, ilustra essa ajuda mútua entre os poucos sociólogos da época diante da precariedade das instituições científicas, para além de rivalidades locais. Na banca de titular de Florestan na USP lá estava Evaristo de Moraes Filho.

39 Dentre estes, Miceli se estabeleceu na FGV-SP e na USP; Paulo Sergio Pinheiro na UNICAMP e depois na USP, Sergio Silva na UNICAMP. Outros ainda, como Lygia Sigaud, Gilberto Velho, Alice de Paiva Abreu, fizeram doutorado em São Paulo, mas eram estabelecidos no Rio, no Museu Nacional e no IFCS-UFRJ.

40 Ver depoimento de Miceli no artigo já citado da revista Piauí em nota anterior. Seria mais improvável que tal leitura ocasional entusiasmada fosse procurada e efetivada fora da literatura canônica por um estudante do universo sociológico das ciências sociais da USP naquele momento; o sucesso institucional também carrega os seus pesos e limites.

41 Miceli é generoso para com os leitores, proporcionando-lhes farto material na direção de uma sólida autoanálise, 
aplicando a si próprio a objetivação de seus trabalhos de pesquisa sobre setores das elites intelectuais (ver seu depoimento em Loureiro, Bastos \& Rego, 2008). Mais distante de seu pai, que atua como dissipador da renda familiar, e próximo de seu tio materno, que lhe apoia em momentos decisivos, e do qual destaca o sobrenome, Miceli desde cedo aguça sua observação e sua sensibilidade a res peito das especificidades de diferentes setores declinantes e emergentes das elites brasileiras.

42 Segundo sua própria apreciação, na entrevista referida, do que seria na USP caso tivesse aceito convite anterior de Leôncio Martins Rodrigues para que já entrasse no Departamento de Sociologia alguns anos antes do que efetivamente entrou. Ver, também, Bastos et al. (2006: 225).

43 Miceli já havia sido nos anos 1980 secretário geral da Associação Nacional de Pós-Graduação e Pesquisa em Ciências Sociais (ANPOCS) durante quatro anos e havia criado, em sua gestão, a Revista Brasileira de Ciências Sociais, desta associação (em 1986). A obra de Bourdieu no final dos anos 1980 já havia se beneficiado de traduções em inglês e se espalhava pelo polo dominante das universidades estadunidenses.

44 A abrangência do trabalho que vinha sendo feito por Afrânio Garcia Jr. junto aos pesquisadores brasileiros relacionados com centros franceses pode ser aquilatada pela dimensão do abaixo-assinado de mais de 450 nomes, além das assinaturas das entidades representativas em ciências sociais, que se seguiu a um manifesto criticando a intervenção da direção da EHESS no CRBC. O abaixo-assinado foi entregue à direção da EHESS em junho de 2008 por Marcelo Ridenti, então secretário geral da ANPOCS, e fez o conselho científico da instituição francesa procurar soluções de incorporação do CRBC a outros centros que não tolhessem as suas linhas de atuação durante mais um ano. Depois disto prevaleceu a rigidez institucional. Tal intervenção da direção da EHESS significava a dissolução da equipe coordenada conjuntamente por Ignacy Sachs e Afrânio Garcia desde 1996.

45 Ver seu artigo "Dominação social, dominação escolar" (2003). 


\section{REFERÊNCIAS BIBLIOGRÁFICAS}

Almeida, Alfredo Wagner de. (1993). Conflitos e mediação: os antagonismos sociais na Amazônia segundo os movimentos camponeses, as instituições religiosas e o Estado. Tese de Doutorado. PPGAS/Museu Nacional, Universidade Federal do Rio de Janeiro.

Almeida, Alfredo Wagner de. (1979). Jorge Amado, política e literatura. Rio de Janeiro: Campus.

Alvim, Rosilene. (1997). A sedução da cidade: os operários camponeses e a fábrica dos Lundgren. Rio de Janeiro: Graphia. Alvim, Rosilene. (1987). Família e operários de origem camponesa: uma leitura da Crise do Brasil arcaico. In: Leite Lopes, José Sergio (org.). Cultura e identidade operária. Rio de Janeiro: Marco Zero/ Ed. UFRJ, p. 123-146.

Alvim, Rosilene. (1979). A arte do ouro: um estudo sobre os ourives de Juazeiro do Norte. Brasília: Ed. UnB (Pesquisa Antropológica, 19).

Aron, Raymond. (1983). Mémoires: 50 ans de réflexion politique. Paris: Julliard (2 vols.).

Arruda, Maria Arminda N. \& Garcia, Sylvia Gemignani (orgs.). (2003). Florestan Fernandes, mestre da sociologia moderna. Brasília: Paralelo 15/CAPES.

Assis, Brian de. (2011). A invenção do intelectual. Piauí, 62, nov., p. 3-14. Disponível em: <http://www.scribd.com/ doc/88791281/A-Invencao-do-Intelectual-vida-e-obra-do-sociologo-brasileiro-Sergio-Miceli>. Acesso em 1 maio 2013.

Bastos, Elide Rugai et al. (2006). Conversas com sociólogos brasileiros. São Paulo: Ed. 34, p. 219-250.

Blanco, Alejandro. (2007). As ciências sociais no Cone Sul e a gênese de uma elite intelectual (1940-1965). Tempo Social, 19/1, p. 89-114.

Boltanski, Luc. (2008). Rendre la réalité inacceptable: à propos de la production de l'idéologie dominante. Paris: Demopolis. Bourdieu, Pierre. (2011). Meditações pascalianas. Tradução de Sergio Miceli. Rio de Janeiro: Bertrand Brasil.

Bourdieu, Pierre (org.). (2007). A miséria do mundo. Petrópolis: Vozes. 
Bourdieu, Pierre. (2005). Secouez un peu vos structures! In: Dubois, Jacques, Durand, Pascal \& Winkin, Yves (orgs.). Le symbolique et le social: la reception internationale de la pensée de Pierre Bourdieu. Liège: Les Éditions de l'Université de Liège, p. 325-341.

Bourdieu, Pierre. (1974). A economia das trocas simbólicas. Introdução, organização e seleção de Sergio Miceli. São Paulo: Perspectiva.

Bourdieu, Pierre. (1972). Esquisse d'une théorie de la pratique. Paris: Seuil.

Bourdieu, Pierre; Chamboredon, Jean-Claude \& Passeron, Jean-Claude. (1983) [1968]. Le métier du sociologue. Paris: Mouton.

Bourdieu, Pierre \& Sayad, Abdelmalek. (1964). Le déracinement. La crise de l'agriculture traditionnelle en Algérie. Paris: Les Éditions de Minuit.

Bourdieu, Pierre et al. (1963). Travail et travailleurs en Algérie. Paris: Mouton.

Brandão Lopes, Juarez R. (1971) [1964]. Sociedade industrial no Brasil. São Paulo: Difel.

Brandão Lopes, Juarez R. (1967). Crise do Brasil arcaico. São Paulo: Difel.

Calhoun, Craig. (2005). Centralité du social et possibilité de la politique. In: Dubois, Jacques, Durand, Pascal \& Winkin, Yves (orgs.). Le symbolique et le social. La réception internationale de la pensée de Pierre Bourdieu. Liège: Éditions de l'Université de Liège (coleção "Sociopolis"), p. 225-256. Cantarino, Eliane. (1988). Da proletarização renovada à reinvenção do campesinato. Tese de Doutorado. PPGAS/Museu Nacional, Universidade Federal do Rio de Janeiro.

Cantarino, Eliane. (1977). Laranja e lavoura branca. Um estudo das Unidades de Produção Camponesa da Baixada Fluminense. Dissertação de Mestrado. PPGAS/Museu Nacional, Universidade Federal do Rio de Janeiro.

Chapoulie, Jean-Michel. (1991). La seconde fondation de la sociologie française, les Etats-Unis et la classe ouvrière. Revue Française de Sociologie, 32/3, p. 321-364.

Delsaut, Yvette. (2005). Entrevista de Pierre Bourdieu com Yvette Delsaut: sobre o espírito da pesquisa. Tempo Social, 17/1, jun., p. 175-210. 
Delsaut, Yvette. (2005). Depoimento sobre Les héritiers. Tempo Social, 17/1, jun., p. 211-228.

Di Tella, Torcuato et al. (1966). Huachipato et Lota; Étude sur la conscience ouvrière dans deux entreprises chiliennes. Paris: CNRS.

Fernandes, Florestan. (1976). A sociologia numa era de revolução social. 2. ed. Rio de Janeiro: Zahar.

Garcia Jr., Afrânio. (2010). Objetivando mudanças sociais em grandes plantações nordestinas: para além do cativeiro de casas-grandes e de senzalas. Um projeto de pesquisas coletivo historicamente situado. Paper apresentado no American Anthropological Association 109th Annual Meeting, 17-20 nov., Nova Orleans.

Garcia Jr., Afrânio. (2009). Fundamentos empíricos da razão antropológica: a criação do PPGAS e a seleção das espécies científicas. Mana, 15/2, out. Disponível em <http:// www.scielo.br/scielo.php?pid=S0104-931320090002 00004\&script=sci_arttext>. Acesso em 2 maio 2013.

Garcia Jr., Afrânio. (1989). O sul: caminho do roçado. São Paulo/Brasília: Marco Zero/Ed. UnB.

Garcia Jr., Afrânio. (1982). Terra de trabalho. Rio de Janeiro: Paz e Terra.

Garcia-Parpet, Marie-France. (2003). Les outsiders dans l'économie de marché: Pierre Bourdieu et les travaux sur l'Algérie. Awal, Cahiers d'Études Berbères, 27-28, p. 139-152. Garcia-Parpet, Marie-France. (1984). Feira e trabalhadores rurais: as feiras do brejo e do agreste paraibano. Tese de Doutorado. PPGAS/Museu Nacional, Universidade Federal do Rio de Janeiro.

Garcia-Parpet, Marie-France. (1977). O Bacurau: Étude de cas d'un marché situé dans une usina. Dissertação de Mestrado. PPGAS/Museu Nacional, Universidade Federal do Rio de Janeiro.

Guillaume, Marc (org.). (1986). L'état des sciences sociales en France. Paris: La Découverte.

Heredia, Beatriz. (1989). Formas de dominação e espaço social. São Paulo: Marco Zero.

Heredia, Beatriz. (1982). A morada da vida. Rio de Janeiro: Paz e Terra. 
Kalinowski, Isabelle. (2005). La science, profession \& vocation; suivi de leçons wébériennes sur la science \& la propagande. Marseille: Agone.

Landim, Leilah. (1993). A invenção das ONGs. Do serviço invisível à profissão sem nome. Tese de Doutorado. PPGAS/Museu Nacional, Universidade Federal do Rio de Janeiro.

Landim, Leilah. (1978). A cooperativa do trabalhador. Diferenciação social e organização camponesa. Dissertação de Mestrado. PPGAS/Museu Nacional, Universidade Federal do Rio de Janeiro.

Leite Lopes, José Sergio. (2009). A ponta do novelo: em busca da trajetória de Lygia Sigaud. Mana, 15/1, p. 257-278.

Leite Lopes, José Sergio. (2005). Pierre Bourdieu et le renouveau des enquêtes ethnologiques et sociologiques au Brésil. In: Dubois, Jacques; Durand, Pascal \& Winkin, Yves (orgs.). Le symbolique et le social. La réception internationale de la pensée de Pierre Bourdieu. Liège: Éditions de l'Université de Liège (coleção “Sociopolis"), p. 103-112.

Leite Lopes, José Sergio. (2003a). Pierre Bourdieu et le renouveau des enquêtes ethnologiques et sociologiques au Brésil. Awal. Cahier d'Études Berbères, 27-28 (n. esp. "L'autre Bourdieu"), p. 169-178.

Leite Lopes, José Sergio. (2003b). A recepção dos trabalhos de Pierre Bourdieu e a renovação das análises sobre as classes populares brasileiras. Revista de Cultura Vozes, 97/4, p. 5-21.

Leite Lopes, José Sergio. (1987a). Introdução. In: Cultura e identidade operária. Rio de Janeiro: Marco Zero/Ed. UFRJ, p. 11-32.

Leite Lopes, José Sergio. (1987b). Sobre os trabalhadores da grande indústria na pequena cidade: crítica e resgate da Crise do Brasil arcaico. In: Cultura e identidade operária. Rio de Janeiro: Marco Zero/Ed. UFRJ, p. 147-170.

Leite Lopes, José Sergio; Pessanha, Elina \& Ramalho, José Ricardo. (2012). Esboço de uma história social da primeira geração de sociólogos do trabalho e dos trabalhadores no Brasil. Educação \& Sociedade, 33, jan./mar., p. 115-129. Disponível em <http://dx.doi.org/10.1590/S0101-7330201 2000100008>. Acesso em 1 maio 2013. 
Lescourret, Marie-Anne. (2008). Pierre Bourdieu. Vers une économie du Bonheur. Paris: Flammarion ("Grandes Biographies").

Loureiro, Maria Rita; Bastos, Elide Rugai \& Rego, José Marcio R. (orgs.) (2008). Conversas com sociólogos brasileiros: retórica e teoria na história do pensamento sociológico do Brasil. Relatório de Pesquisa n. 11, FGV-EAESP/GVPesquisa. Disponível em <http://gvpesquisa.fgv.br/sites/gvpesquisa.fgv.br/files/publicacoes/Rel112008.pdf >. Acesso em 2 maio 2013.

Loyola, Maria Andrea. (1984). Médicos e curandeiros: conflito social e saúde. São Paulo: Difel.

Loyola, Maria Andrea. (1983). L'éspirit et le corps: des thérapeutiques populaires dans la banlieue de Rio. Paris: Éditions de la Maison des Sciences de l'Homme.

Loyola, Maria Andrea. (1982). Cure des corps et cure des âmes. Les rapports entre les medicines et les religions dans la banlieue de Rio. Actes de la Recherche en Sciences Sociales, 43, p. 3-45.

Mariani, Maria Clara. (1982). Educação e ciências sociais: o Instituto Nacional de Estudos e Pesquisas Educacionais. In: Schwartzman, Simon (org.). Universidades e instituições científicas no Rio de Janeiro. Brasília: CNPq, p. 167-195.

Miceli, Sergio. (1989). História das ciências sociais no Brasil. São Paulo: Vértice/Editora Revista dos Tribunais/IDESP (vol. 1).

Moore Jr., Barrington. (1987) [1978]. Injustiça; as origens sociais da obediência e da revolta. São Paulo: Brasiliense.

Moraes Filho, Evaristo de. (1979) [1951]. O problema do sindicato único no Brasil. São Paulo: Alfa-Ômega.

Novaes, Regina. (1997). De corpo e alma: catolicismo, classes sociais e conflitos no campo. Rio de Janeiro: Graphia.

Novaes, Regina. (1978). Os escolhidos. Doutrina religiosa e prática social. Dissertação de Mestrado. PPGAS/ Museu Nacional, Universidade Federal do Rio de Janeiro.

Palmeira, Moacir. (1994). Memorial para o concurso de professor titular. Museu Nacional-UFRJ. Rio de Janeiro: Biblioteca Francisca Keller do PPGAS-MN-UFRJ, mimeo.

Palmeira, Moacir. (1971). Latifundium et capitalisme. Lecture critique d'un débat. Thèse de 3e. Cycle. Université de Paris. 
Palmeira, Moacir et al. (1977). Emprego e mudança sócio-econômica no Nordeste. Anuário Antropológico, 76, p. 201238.

Pinheiro Filho, Fernando Antonio. (2009). The renovation: aspects of Pierre Bourdieu's reception in Brazil. Sociologica, 1. Disponível em <http://www.rivisteweb.itdoi/10.2383/ 29574>. Acesso em 3 fev 2013.

Pollak, Michael. (1996a). Max Weber: elementos para uma biografia sócio-intelectual, parte I. Mana, 2/1, p. 59-96.

Pollak, Michael. (1996b). Max Weber: elementos para uma biografia sócio-intelectual, parte II. Mana, 2/2, p. 85-114.

Reynaud, Jean-Daniel \& Bourdieu, Pierre. (1966). Une sociologie d'action est-elle possible? Revue Française de Sociologie, 7/4, p. 508-517.

Rinaldi, Doris. (1978). A terra do santo e o mundo dos engenhos. Estudo de uma comunidade rural nordestina. Dissertação de Mestrado. PPGAS/ Museu Nacional, Universidade Federal do Rio de Janeiro.

Sabóia, Anita (org.). (2000). Catalogue general de thèses sur le Brésil, 1823-1999. Cahiers sur le Brésil Contemporain, hors série, 354p.

Saint-Martin, Monique de. (2003). Dominação social, dominação escolar. Educação \& Realidade, 28/1, jan.-jul., p. 2129. Disponível em <http://seer.ufrgs.br/educacaoerealidade/article/download/25659/14990>. Acesso em 2 maio 2013. Sigaud, Lygia. (2008). A collective ethnographer: fieldwork experience in the Brazilian Northeast. Information sur les Sciences Sociales, 47, p. 71-97.

Sigaud, Lygia. (1979a). A nação dos homens. Anuário Antropológico, 78, p. 13-116.

Sigaud, Lygia. (1979b). Os clandestinos e os direitos. São Paulo: Duas Cidades.

Sociologie du Travail (1961). número especial, contém dossiê: "La classe ouvrière au Brésil", 1961.

Swartz, David. (1998). Culture and Power: the sociology of Pierre Bourdieu. Chicago: University of Chicago Press.

Tanguy, Lucy. (2011). La Sociologie du Travail em France; enquete sur le travail des sociologies, 1950-1990. Paris: La Découverte. 
TOURAINE E BOURDIEU NAS CIÊNCIAS SOCIAIS BRASILEIRAS: DUAS RECEPÇÕES DIFERENCIADAS

78

Touraine, Alain. (1977). Un désir d'histoire. Paris: Stock.

Touraine, Alain. (1966). La raison d'être d'une sociologie de l'action. Revue Française de Sociologie, 7/4, p. 518-527.

Touraine, Alain. (1955). L'évolution du travail ouvrier aux usines Renault. Paris: CNRS.

Touraine, Alain \& Ragazzi, Oretta. (1961). Ouvriers d'origine agricole. Paris: Études Sociologiques aux Éditions du Seuil. 
Palavras-chave

Bourdieu; Touraine;

Campo intelectual;

Recepção; Ciências sociais brasileiras.

Keywords

Bourdieu; Touraine;

Intellectual field;

Reception; Social history

of Brazilian

social sciences.

\section{TOURAINE E BOURDIEU NAS CIÊNCIAS SOCIAIS} BRASILEIRAS: DUAS RECEPÇÕES DIFERENCIADAS

\section{Resumo}

Ao retomar o tema da recepção da obra de Pierre Bourdieu no Brasil, o presente artigo o faz a partir da comparação com a recepção de outro sociólogo francês, Alain Touraine, anteriormente implantado na circulação de ideias e redes de pesquisadores entre os dois países. A trajetória dos dois no que diz respeito à sua relação com o campo das ciências sociais brasileiras pode ser uma pista interessante para o conhecimento de aspectos deste mesmo campo no que se refere à sua inserção na circulação internacional de ideias e de pesquisadores. A bagagem acumulada de sociologia industrial de Touraine fez com que fosse procurado pela sociologia uspiana no momento em que as pesquisas sobre o fenômeno industrial de São Paulo eclodiam. Já a apropriação de Bourdieu incide sobre gerações subsequentes, e, ao ter adquirido renome nos anos 1990 nos países anglo-saxônicos, já era bem conhecido nos círculos especializados brasileiros.

\section{TOURAINE AND BOURDIEU IN THE BRAZILIAN SOCIAL SCIENCES: TWO DIFFERENTIATED RECEPTIONS}

\section{Abstract}

This article compares the reception of Pierre Bourdieu's with that of Alain Touraine's within the Brazilian social sciences. At the time when Brazilian social scientist became acquainted with Bourdieu's work, Touraine's ideas already belonged to the international circulation of ideas and scholars between France and Brazil. The trajectory of both French sociologists in regard with the field of Brazilian social sciences is an interesting lead for understanding the position of this same field within the international circulation of ideas and scholars. The sociologists of the University of São Paulo invited Touraine, with his intellectual background in industrial sociology, at the time when studies about the industry in the metropolis were flourishing. By contrast Bourdieu's work was appropriated by subsequent generations of scholars. When Bourdieu acquired fame in Anglo-American countries in the nineties he was already well known by Brazilian specialists. Some of his research tools were appropriated by within these new generations of the social sciences' field. 